\title{
O ESTUDO GEOGRÁFICO DO USO DO NOME SOCIAL NO EXAME NACIONAL DO ENSINO MÉDIO: A ENTRADA DA POPULAÇÃO TRANS NO ENSINO SUPERIOR.
}

\author{
Rebecka de França ${ }^{1}$; João Paulo Teixeira Viana ${ }^{2}$, Jeam Claude Gomes de Souza ${ }^{3}$, Maria do \\ Socorro Pessoa Fé ${ }^{4}$; Levi Rodrigues de Miranda ${ }^{5}$
}

\section{RESUMO}

O presente trabalho traz à tona uma pesquisa de grande importância para o âmbito da geografia que é o estudo da diversidade social no âmbito da ciência geográfica, estudar o gênero e suas particularidades é de grande valia, pois consegue compreender as relações sociais. O objetivo central é analisar a importância da utilização do nome social no Exame Nacional do Ensino Médio (ENEM) com relação aos percentuais de adereção a essa nova conquista. $O$ trabalho se justifica mediante a necessidade de ter estudos voltados para a área LGBT's dentro da ciência geográfica, a mesma por ser um amplo campo de estudo multidisciplinar e que conseguem percorrer por diversos vieses. Além disso, é notório que estudo como esses são escassos na academia, sendo assim, uma maior contribuição para a temática LGBT’s no Brasil. A pesquisa faz uso de pesquisas referenciais e bibliográficas com relação a conquista por parte das travestis e transexuais no direito da utilização do nome social em diversos processos seletivos como é o caso do Enem, bem como em artigos e postulado concernentes a temática, uma vez que existe poucos estudos na área, bem como escassos artigos e resumos sobre o uso do nome social. $\mathrm{O}$ artigo está dividido de forma sequencial e objetiva, onde será possível entender a utilização do nome social na constituição federal, e sua alocação na atualidade, bem como o processo que se deu essa nova adequação no Exame Nacional do Ensino Médio. O uso do nome social é um importante direito que as travestis e transexuais conseguiram, um direito constitucional da cidadania.

Palavras-chave: Transexuais. Travestis. Geodiversidade. ENEM.

\section{RESUME}

The present work brings to light a research of great importance for the geography scope, which is the study of social diversity within the scope of geographic science, studying gender and its particularities is of great value, as it manages to understand social relations. The central objective is to analyze the importance of using the social name in the National High School Exam (ENEM) in relation to the percentage of adherence to this new achievement. The work is justified by the need to have studies focused on the LGBT's area within the geographic science, the same for being a wide field of multidisciplinary study and able to traverse through several biases. In addition, it is notorious that I study such as these are scarce in academia, thus making a greater contribution to the LGBT's theme in Brazil. The research makes use of referential and bibliographic researches regarding the conquest by transvestites and transsexuals in the right to use the social name in various selection processes, such as Enem, as well as in articles and postulates concerning the theme, since there are few studies in the area, as well as few articles and abstracts on the use of the social name. The article is divided sequentially and objectively, where it will be possible to understand the use of the social name in the federal constitution, and its allocation today, as well as the process that this new adaptation took place in the National High School Exam. The use of the social name is an important right that transvestites and transsexuals have achieved, a constitutional right of citizenship.

Keywords: Transsexuals. Transvestites. Geodiversity. AND EITHER.

\section{INTRODUÇÃO}

Todas as coisas têm nome Casa, janela e jardim Coisas não tem sobrenome, mas a 
gente sim Todas as flores têm nome rosa, camélia e jasmim Flores não têm sobrenome, mas a gente sim. (GRIFO NOSSO).

O presente trabalho traz como enforque o estudo acerca da importância do uso do nome social no Exame Nacional do Ensino Médio, importante meio de acesso à educação superior e que tem se tornado um grande aparato para o acesso de diferentes grupos sociais, dentre eles as travestis e transexuais (homens e mulheres). A metodologia utilizada foi a pesquisa referencial e bibliográfica em artigos e postulados acerca da temática, bem como em sites governamentais com a finalidade de obter dados pertinentes a pesquisa, como o IBGE e o Ministério da Educação. A opção pela temática diz respeito a condição da autora enquanto pertencente ao grupo "trans", bem como a jornada acadêmica, desde ao uso do nome social no ENEM e sua visão enquanto acadêmica da geografia. Por fim, a pesquisa passará por análise sobre estatísticas concernentes entre anos, desde ao direito e uso do nome social e sua aplicabilidade atual. Assim, será possível ver de forma sequencial e objetiva o uso e direito do nome social segundo a constituição federal e suas prerrogativas, bem como sua utilização na atualidade e as principais barreiras encontras, como também a importância desta no Exame Nacional do Ensino Médio (ENEM).

\section{O uso e direito à cidadania da constituição federal}

Ainda que a Constituição Federal de 1988 traga o conceito de cidadania ampliada, as pessoas trans ainda são excluídas de seus direitos e de uma perspectiva de vida com qualidade, dignidade, respeito, e segurança, o que resulta na marginalização social e na violência psicológica, moral e física.

Nesse sentido Pontes de Miranda assevera:

A imposição do prenome (impositio nominis) só se opera com o registro do nascimento. Quaisquer outros prenomes, que se tenha usado, ou em participações de nascimento, ou matrículas em escolas, ou passaportes, ou (irregulares) carteiras de identidade, não entram no mundo jurídico e nenhuma eficácia têm.

Como aponta Freire (2013):

"A heteronormatividade que cerca as vivências da sexualidade nas chamadas "sociedades ocidentais" fazem com que a heterossexualidade seja encarada como a "expressão sexual normal", tudo que foge desse contexto é tido como anormal,"

Desta forma, é notório a perseguição a este recorte populacional por conta de sua identidade de gênero e orientação sexual que foge do contexto tido como "normal" que rege as culturas ocidentais. 


\section{O uso do nome social na atualidade}

No mundo contemporâneo, uma das maiores lutas do movimento trans é o respeito à identidade de gênero, ao nome social e ao tratamento condizente ao gênero. Contudo, o que se ressalta no país é a absoluta ausência de uma legislação que garanta os direitos fundamentais às pessoas trans, como uma lei de identidade de gênero, por exemplo, apesar de vários projetos já terem sido apresentados no Congresso Nacional. Segundo Bento (2014), foi a partir de 2008, que no Brasil, observam-se mobilizações dos Movimentos Sociais de Lésbicas, Gays, Travestis e Transexuais (LGBT) pela utilização do nome social pelas escolas públicas estaduais nos registros escolares, considerando os altos índices de evasão escolar dessa população, que é impossibilitada de permanecer na escola pública por ser vítima de preconceito e discriminação, ainda usando Bento (2014) é necessário afirmar que a construção do corpo durante o período escolar é extremamente excludente para a população trans, deste modo, prevalece o entendimento de que gênero corresponde a uma construção social. Segundo Marcia Aran, Daniela Murta e Tatiana Lionço:

[...] o transexualismo continua a ser visto como uma síndrome, identificada pelo Transtorno de Identidade de Gênero - TIG, considerado um estado psicológico no qual a identidade de gênero está em desacordo com o sexo biológico e em que existe uma pulsão psicológica de pertencer ao sexo oposto ao genético, sempre acompanhada de um desejo obsessivo de libertar-se de sua genitália para adquirir a do sexo oposto.

A autora explica que essa construção do gênero com base em suas experiências com pessoas que se sujeitam ao processo transexualizador do SUS (hormonioterapia e cirurgia de readequação sexual), conseguem expressar suas angustias e demonstram a ela os principais problemas referentes a esse processo, dentre os principais obstáculos narrados, é possível identificar a ausência da escola, da família e do mais importante - do amor.

Para Cerqueira (2015), em todo o Brasil, o primeiro diploma normativo que se tem notícia a regular a utilização do nome social foi editado pela Secretaria de Estado de Educação do Estado do Pará que, por meio da Portaria no . 16/2008-GS, estabeleceu, de forma sucinta que: “a partir de 02 de janeiro de 2009, todas as Unidades Escolares da Rede Pública Estadual do Pará passarão a registrar, no ato da matrícula dos alunos, o prenome social de travestis e transexuais".

Já a Associação Brasileira de Gays, Lésbicas, Bissexuais, Travestis e Transexuais (ABGLT), afirma que foi a Universidade Federal do Amapá foi pioneira na adoção do nome social para seus alunos. O nome social deve ser utilizado por pessoas auto classificadas como nominadas trans, que preferem ser nominadas dessa forma no cotidiano, refletindo a sua expressão de gênero, em contraposição ao nome do registro civil, que foi atribuído em 
consonância com o gênero ou/e o sexo quando do nascimento. Ressalta-se que o outro conceito foi atribuído ao nome social na ADI-4275, em trâmite perante o STF, como apelido público e notório, pelo qual as pessoas são identificadas pela família e amigos.

Em decretos e portarias que tratam do assunto encontra-se também o nome social, como nome pelo qual o travesti e transexual se identifica e é identificado junto a sociedade em que vive:

Art. $1^{\circ}$ - Fica assegurado aos servidores públicos, no âmbito da Administração Pública Federal direta, autárquica e fundacional, o uso do nome social adotado por travestis e transexuais. Parágrafo único. Entende-se por nome social aquele pelo qual essas pessoas se identificam e são identificadas pela sociedade.

De acordo com Cerqueira (2015), o instituto do "Nome Social", é novo, entretanto está a se difundir em passo acelerado entre os vários entes federativos. O nome social é aquele pelo qual as pessoas travestis e transexuais se reconhecem, bem como são identificadas por sua comunidade e em meio comunitário. É, assim sendo, o nome usualmente empregado nas relações diárias do indivíduo, uma vez que a vida diária não exige os rigorismos da exibição de documentos oficiais para interagir com outras pessoas.

\section{A utilização do nome social no ENEM}

Desde 2014 o Enem travestis e transexuais podem ser identificados/as pelo nome social nos dias e locais de realização das provas. Para isso, os/as candidatos/as necessitam fazer uma solicitação ao Instituto Nacional de Estudos e Pesquisas Educacionais (Inep), como êxito desta política vale salientar que desde que o direito de usar o nome social foi adotado, houve um crescente número de pessoas trans adentrando as portas das universidades, o nome social não só convidou a esta população a se submeter ao exame, como abriu as portas do ensino superior para este segmento.

O nome social surge no Enem após várias denúncias e reclamações na mídia pelo constrangimento que pessoas trans sofreram na hora de apresentar o documento de identidade aos fiscais das salas de prova, desde atraso da entrega de caderno de provas pela demora de conferência de dados a relatos de humilhações e discriminação por parte dos fiscais. Em 2014, 102 pessoas trans usaram o nome social durante a aplicação da prova, em 2015 esse número passou para 278. Em 2016, o número cresceu 46\%, dos 842 pedidos, 408 foram atendidos.

De acordo com o Instituto Nacional de Estudos e Pesquisas (Inep), 432 pedidos foram recusados neste ano porque os participantes não encaminharam a documentação exigida em edital. Os outros dois foram de candidatos que conseguiram o registro civil com o nome social. 


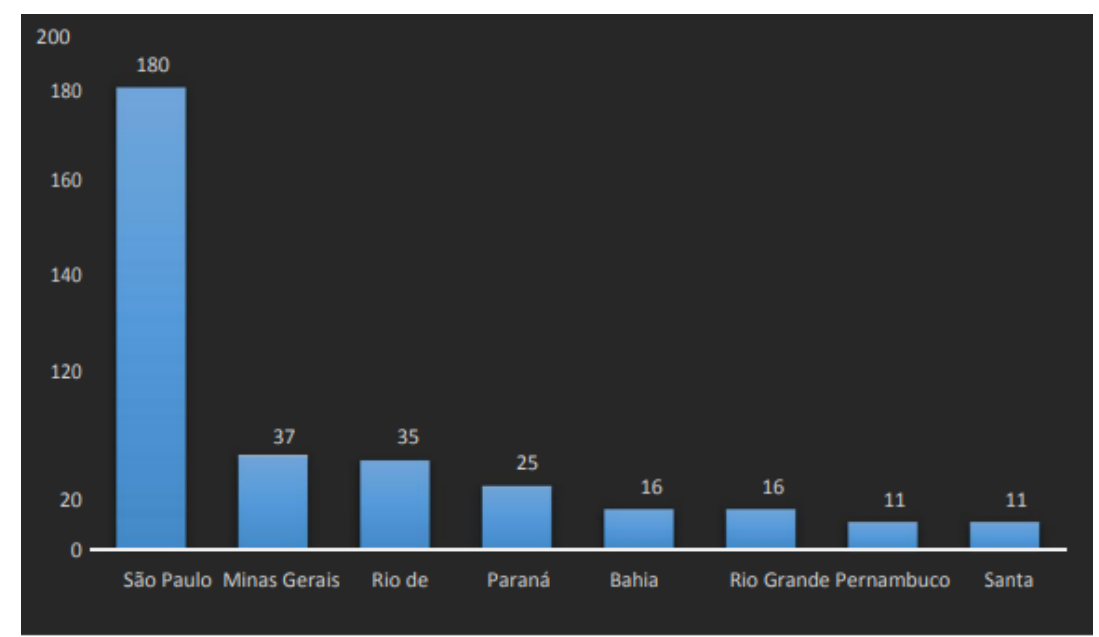

Fonte: FRANÇA, R. de; NOGUEIRA, S. N. B. Com dados do INEP.

Gráfico 2 - o uso do nome social no enem em 2016 por estado

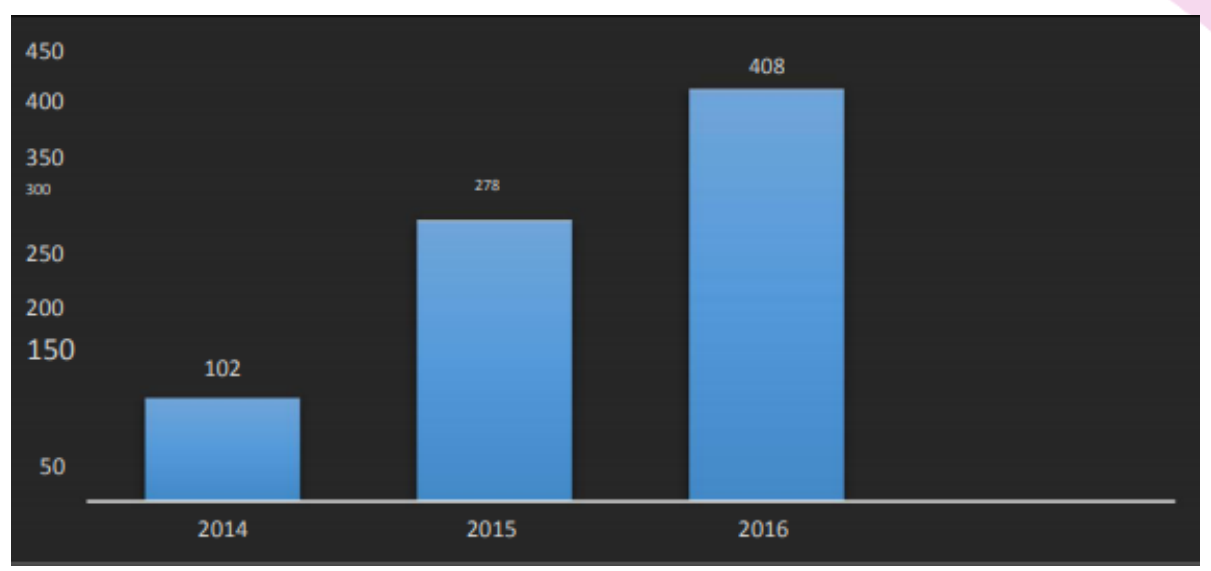

Fonte: FRANÇA, R. de; NOGUEIRA, S. N. B. com dados do INEP.

Desde 2015, São Paulo é o Estado com o maior número de solicitações atendidas: 89 em 2015 e 180 em 2016. O segundo estado com mais transvestis e transexuais que conquistaram o direito de usar o nome social no Enem deste ano foi Minas Gerais (37), seguido por Rio de Janeiro (35), Paraná (25), Bahia e Rio Grande do Sul (16 cada), Pernambuco e Santa Catarina (11 cada). Os demais estados tiveram menos de dez inscrições cada, desta forma, também pode se apontar a procura nos outros estados que não foram citados devido à pouca procura ou não saberem do uso dessa política. Com estes números foi possível comprovar que esta população, vive em todo o território nacional e solicitou o nome social em quase todos os estados da unidade federativa.

Os/as candidatos/as travestis e transexuais que realizarão o Exame Nacional do Ensino Médio (Enem) 2017 tiveram entre 29 de maio e 4 de junho para pedir o uso do nome social no exame. Os pedidos poderão ser feitos a partir das $10 \mathrm{~h}$. Inscrições para a prova, que acontece em 5 e 12 de novembro vão até 19 de maio. A taxa de inscrição, foi de R \$ 82, e pode ser paga até 
o dia 24 de maio.

Os interessados deverão enviar cópia do documento de identificação, formulário preenchido e foto recente pelo sistema de inscrição. No dia das provas, as pessoas trans deverão ser tratadas pelo nome com o qual se identificam e também deverão utilizar o banheiro do gênero com o qual se identificam. Para realizar a solicitação, os participantes devem dispor dos seguintes documentos: fotografia nítida, atual, individual, colorida, com fundo branco que enquadre desde a cabeça até os ombros; cópia digitalizada da frente e verso de um dos documentos oficiais com foto; e cópia assinada e digitalizada do formulário de solicitação de atendimento pelo nome social que será disponibilizado na Página do Participante às $10 \mathrm{~h}$ do dia 29 de maio.

\section{CONDIDERAÇÕES FINAIS}

Observa-se que com a utilização do nome social e posteriormente ser uma lei e por direito a todos e qualquer indivíduo que traga o gênero como característica social e é de grande valia, pois se for analisar um passado não tão distante, esse direito era irracional e inconstitucional, pois via as transexuais e travestir com um olhar de preconceito patológico. Embora seja uma grande conquista, a um grande empecilho que é a comprovação para a utilização do nome social, pois faz o indivíduo passar por um momento de "comprovação de existência", algo que caracteriza que algum deste grupo esteja mentindo ou utilizando o direito de má fé, como consequência disto a um certo receio em participar de processos seletivos como o ENEM. Em suma, é uma conquista a ser trabalhada e discutida, não deixa da forma que está, mas aumentar fórum de debates e discussões que tratem em deixar o acesso ao nome social algo mais simplificado e objetivo, sem a necessidades de grandes comprovações, dá ao ser humano seu poder de escolha, sua liberdade de ser o que quer e o que seja. Mas sem dúvidas o grande feito do uso dessa política foi de aumentar o número de pessoas trans cursando o ensino superior por todo o país, ainda não foram divulgados números pelas ONGS que pesquisam essa população, uma vez que o governo não se preocupa em apontar tais estatísticas, o movimento LGBT do Brasil segue fazendo papel de Estado na divulgação positiva dessa politica para a população trans brasileira.

\section{REFERÊNCIAS}

AGÊNCIA BRASIL. Aumenta o uso do nome social por travestis e transexuais no Enem 2016. ÚltimoSegundo,IG,12/10/2016.Disponível em: . Acesso em 12 mai. 2017.

ARAN, Márcia; MURTA, Daniela e LIONÇO, Tatiana. Transexualidade e saúde pública no 
Brasil. Cienc. Saúde coletiva. V14, n.4. p.1141-1149, jul/ago.2009. in http://www.scielo.br/scielo.php?script=sci_arttext\&pid=S141381232009000400020\&lng=pt \&nrm=iso, acessado em 19 jun. 2013.

BENTO, Berenice. A reinvenção do corpo: sexualidade e gênero na experiência transexual. $2^{\mathrm{a}}$ edição - Natal: EDUFRN. 2014. BENTO, Berenice. Nome social para pessoas trans: cidadania precária e gambiarra legal. Contemporânea - Revista de Sociologia da UFSCar, São Carlos, v. 4, n. 1, jan.-jun. 2014, pp. 165-182. Disponível em: . Acesso em 12 mai. 2017.

CERQUEIRA, Rodrigo Mendes. Nome social: propósito, definição, evolução histórica, problemas e particularidades. Revista Jus Navigandi. Teresina, ano 20, n. 45219, 12 dez. 2015. Disponível em: . Acesso em 12 mai. 2017.

FREIRE, L. Configurando identidades: os múltiplos processos de construção de identidades homossexuais masculinas de jovens universitários no Rio de Janeiro.

Bagoas: revista de estudos gays, Natal, v. 1, n. 1, p. 217-240, jul./dez. 2007. GAGLIANO, Pablo Stolze. Novo curso de direito civil: 2. ed. São Paulo: Saraiva 2002, v. I.

MIRANDA, Francisco Cavalcanti Pondes de. Tratado de direito privado: Campinas, Bookseller, 2000, v. III. 